\title{
The influence of socioeconomic status and birth weight on blood pressure of Indonesian pre-pubertal children
}

\author{
Madarina Julia $^{1}, \mathrm{MM}$ van Weissenburch ${ }^{2}$, HA Delemarrevan de Waal ${ }^{2}$, Achmad Surjono ${ }^{1}$
}

\begin{abstract}
Background It has been shown that elevated blood pressure (BP) in childhood contributes to the development of coronary artery disease, cerebrovascular accidents, heart failure, and renal failure in adults. There is also evidence of some correlations between childhood BP and BP in adulthood. Obesity as well as low birth weight are a risk factors for elevated BP, both in children and in adults. Most epidemiological studies have also shown a relationship between high $\mathrm{BP}$ and socioeconomic status (SES).

Objective To assess the influence of socioeconomic status and birth weight on blood pressure of school-aged prepubertal children living in Indonesia.

Methods A cross-sectional survey on 2922 school-aged prepubertal children from the rural, poorurban and nonpoor urban communities was performed. Data on age, sex, stature, BMI, birth weight, systolic and diastolic BP were collected from all children. Results Overall and within every socioeconomic status group, blood pressures were positively associated with stature and body mass index (BMI). Children from poor-socioeconomic families, i.e. rural and poor urban, had significantly lower height and BMI, and hence, in the unadjusted analyses, poor socioeconomic status was associated with lower systolic and diastolic BP. However, after adjustment for age, sex, stature and BMI, rural children were found to have significantly higher systolic BP compared to nonpoor urban children, with regression coefficient (95\% CI) of 1.19 (0.42 to 1.96). Birth weight was not associated with blood pressure in childhood.

Conclusion This study indicated that for a given stature and BMI, poor children had a higher systolic BP [Paediatr Indones 2007;47:270-277].
\end{abstract}

Keywords: socioeconomic status, blood pressure, prepubertal children, Indonesia
I t has been shown that elevated blood pressure (BP) in childhood contributes to the development of coronary artery disease, cerebrovascular accidents, heart failure, and renal failure in adults. ${ }^{1}$ There is also evidence of some correlations between childhood BP and BP in adulthood. ${ }^{2}$ Moreover, elevated BP in childhood, along with obesity, is significantly associated with carotid vascular changes and increased left ventricular mass, both in children and adults. ${ }^{3-5}$ Obesity as well as low birth weight are a risk factors for elevated BP, both in children and in adults. ${ }^{6-9}$ Most epidemiological studies have also shown a relationship between high BP and socioeconomic status (SES). ${ }^{10,11}$ In industrialized countries, individuals of lower SES have been reported to have higher blood pressure both during childhood

Part of this paper has been published in Journal of Human Hypertension 2006; 20:546-8 as a research letter. The article is published with permission of The Editor of Journal of Human Hypertension.

From the Department of Child Health, Medical School, Gadjah Mada University, Sardjito Hospital, Yogyakarta, Indonesia (MJ, AS) ${ }^{1}$. Department of Pediatrics and Research Institute for Clinical and Experimental Neurosciences, VU University Medical Center, Amsterdam, The Netherlands (MMVW, HADDW) ${ }^{2}$.

Reprint requests to: Madarina Julia, MD, Department of Child Health, Medical School, Gadjah Mada University, Sardjito Hospital, Jl. Kesehatan no. 1, Sekip Utara, Yogyakarta 55281, Indonesia. Tel. 62-274-561616. Ext.221. Fax.62-274-583745. Email: madarinajulia@yahoo.com 
and adulthood, which may be related to obesity, since obesity is more prevalent among this population. ${ }^{12}$ However, at present, in contrast to the Western populations, obesity is not a problem among people of lower socioeconomic class in developing countries. ${ }^{13}$ In industrialized countries there is consistently negative association between SES and BP while in developing countries this association vary. ${ }^{11,14-16}$ The basis of these inconsistent association of SES and BP in developing countries is not clear. It might be due to the variation in the stages of modernization, economic development or adoption of westernized lifestyles between various communities. ${ }^{15}$ One of the most marked societal and environmental changes in developing countries is urbanization. ${ }^{17,18}$ With urbanization, a marked increase in consumption of energy rich as well as salted foods and a decrease in energy expenditure through less physical activity is observed. ${ }^{19,20}$

Low childhood socioeconomic circumstances have been shown to have long lasting negative influences on adult health, i. e., poorer cardiorespira-tory fitness, higher systolic BP, and higher prevalence of obesity, irrespective of where one ends-up in the socioeconomic hierarchy as an adult. ${ }^{21,22}$ The effect of these adverse socioeconomic circumstances might or might not associated with preand postnatal growth. ${ }^{22,23}$ Therefore, the aim of the present study was to evaluate the association between nutritional status and SES of school aged prepubertal children living in Indonesia. The contribution of birth weight on the actual blood pressure in the population studied was also taken into account.

\section{Methods}

\section{Study population and design}

The study was performed in two adjacent areas in Central Java. Yogyakarta, an urban area, was a city with 487,115 inhabitants at the time of the study. Gunung Kidul, a rural area located about 20 to $40 \mathrm{~km}$ from Yogyakarta, had 710,691 inhabitants. ${ }^{24}$ We chosed these two areas because of the relatively homogeneous ethnicity of their populations. Most of the people in both areas were of Javanese descent. The altitude of both study areas is less than $500 \mathrm{~m}$ above sea level. ${ }^{24}$

A cross-sectional study was conducted on schoolaged prepubertal children in both areas. We randomly selected 33 of 509 public primary schools in the rural area and 37 of 172 public primary schools in the urban area. In Indonesia, it is obligatory for children to enter primary school at the age of six and seven years. Prepubertal children (under eight years old for girls and under nine years old for boys) from the first-and secondyear class of every school were included. The results of the study on anthropometric status of these prepubertal children had been reported else where. ${ }^{25}$

We excluded children with prominent chronic diseases, such as congenital heart disease or major thalassemia as well as children with physical handicaps that might interfere with the measurements. The study was performed from February to May 1999 and was approved by the ethical committee of Gadjah Mada University, Yogyakarta, Indonesia.

\section{Data collection}

Anthropometric data were collected by health professionals. Heights and weights were measured using the standard techniques described by the World Health Organization (WHO). ${ }^{26}$ Training for standardization of the measurements, followed by field practice and testing, was performed prior to data collection. All measurements were performed between 8 and 10 a.m. The children, wearing light clothing, were weighed to the nearest $0.1 \mathrm{~kg}$ with a Seca digital scale (Germany). Height was measured to the nearest $0.1 \mathrm{~cm}$ with a portable stadiometer. Right mid-upper-arm circumference was measured at a point midway between the olecranon and the acromion, using a non-stretchable measurement tape, to the nearest $0.1 \mathrm{~cm}$.

Blood pressure (BP) was measured using the standard techniques described by the Task Force on Blood Pressure Control in Children. ${ }^{27}$ To minimize the children's apprehension, a physician, helped by the teacher in the class, first explained the procedure of blood pressure measurement to all children. All measurements were performed in the classrooms of the children by one physician using one mercurygravity manometer (Riester, Germany). After at least 10 minutes rest from recent activity, children were asked to sit in a comfortable sitting position with their right arm fully exposed and resting on a supportive surface at the heart level. Blood pressures were measured on the right arm, using appropriate cuff size, 
i.e. a children cuff, when their arm circumferences were less than $18 \mathrm{~cm}$, or a small adult cuff when their arm circumferences were $18 \mathrm{~cm}$ or above.

The cuff was then rapidly inflated to about 20 $\mathrm{mm} \mathrm{Hg}$ above the point at which the radial pulse disappears. The pressure within the cuff is then released at a rate about 2 to $3 \mathrm{~mm} \mathrm{Hg}$ per second while auscultation was performed over the brachial artery. The systolic BP was determined by the onset of the "tapping" Korotkoff sound. The diastolic BP were defined as the muffling of the Korotkoff sounds (the fourth Korotkoff sound)., ${ }^{1,27}$ Both systolic and diastolic BP were recorded to the nearest $2 \mathrm{~mm} \mathrm{Hg}$.

Information on birth weight was collected using a questionnaire sent to the parents with the help of the teachers. Birth dates were verified by the child's birth certificate. Definitions of rural and urban populations were based on agricultural activities and population densities. Yogyakarta had a population density of $14,988 / \mathrm{km}^{2}$, while Gunung Kidul had a population density of $498 / \mathrm{km}^{24}$ In the urban area, the socioeconomic status of each child was individually deduced from his or her living environment. Children living in the urban slum area were considered poor, and those not living in this area were considered to be not poor.

\section{Statistical analyses}

The body mass index (BMI) was calculated by dividing the weight in kilograms by the square of the height in meters $\left(\mathrm{kg} / \mathrm{m}^{2}\right)$. Data on BMI-for-age were converted to $z$-scores based on the year 2000 sex specific Center for Disease Controls and Prevention (CDC) growth charts using the nutritional anthropometry module (NutStat) of the CDC's Epi Info 2000 (Centers for Disease Control and Prevention, Atlanta, Georgia, USA). ${ }^{28}$

Data on height-for-age were also converted to zscores using the same reference and statistical software. Biologically implausible values, such as z-scores below 6.00 or above +6.00 , were excluded from the analysis. Values that were most likely to represent errors, i.e., those with $4 z$-score units outside the observed mean for every age in one full year, were also excluded (flexible exclusion range). Children were classified as stunted if they had height-for-age z-scores (HAZ) below -2.00.28, 29

Children were considered to have low birth weights (LBW) when their birth weights were below the $10^{\text {th }}$ percentile of our study subjects' sex-specific birth weight distribution, and considered to have high birth weights (HBW) when they were above the $90^{\text {th }}$ percentiles. Children born between the $10^{\text {th }}$ and the $90^{\text {th }}$ percentile were considered to have normal birth weight (NBW).

All statistical analyses were performed using SPSS for Windows (Version 9, SPSS, Chicago, Illinois, USA). The mean and distribution of continuous data, i.e. data on age, height-for-age $z$ scores (HAZ), BMI-for age z-scores (BMIZ), systolic and diastolic BP between the three socioeconomic status groups and between the three birth weight groups were compared using t-tests. Estimates differences were presented as mean difference and 95\% confidence interval $(95 \% \mathrm{CI})$.

Univariate regression analyses were used to assess the associations between systolic and diastolic $\mathrm{BP}$ as the dependent variables and socioeconomic status groups, sex, age, HAZ and BMIZ as the independent variables separately. Multiple regression analyses were then performed to estimate the independent contribution of socioeconomic status to blood pressures adjusted for sex, age, HAZ and BMIZ with or without birth weight status. Two sets of multiple regression models were constructed, one set of models was to compare rural to non-poor urban children while the other set was to compare poor urban to non-poor urban children.

To assess predictors of systolic and diastolic BP within the rural, poor urban and non-poor urban children or within the LBW, NBW and HBW children separately, multiple regression models with sex, age, HAZ and BMIZ as the independent variables and systolic and diastolic $B P$ as the dependent variables were constructed for each socioeconomic status and birth weight group. Regression coefficients were presented as unstandardized estimates (95\% CI). Statistical significance $(\alpha)$ was set at $\mathrm{P}<0.05$.

\section{Results}

We visited 70 schools to examine a total of 3689 prepubertal children who were listed as first- and second-year students. We excluded 674 children because they were not in the required age range. Of the remaining 3015 children, four missed the anthropometric measurement session and one had a 
HAZ in the flexible exclusion range.

Of the 3010 children whose anthropometric measurements were available and considered valid, we were able to measure the blood pressure, only 2922 children that is 1169 rural children ( $96 \%$ of the eligible rural children) and 1753 urban children (98\%). The characteristics of 88 children without blood pressure measurements were comparable to those with blood pressure measurement except that they were significantly older.

Children from the urban area were then subdivided into 431 poor (from the urban slum area) and 1322 non-poor. The total population studied consists of 1690 (57.8\%) boys and 1232 girls. The three groups did not differ with respect to the ratio of males to females $(\mathrm{P}=0.05)$, i.e. $59 \%, 58 \%$ and $57 \%$ boys in the rural, poor urban and non-poor urban, respectively.

Rural and poor urban children had significantly lower mean height-for-age z-scores (HAZ) and BMIfor-age Z-scores (BMIZ), compared to non-poor urban children (Table 1). The overall prevalence of stunted growth, i.e. HAZ $<-2.00$, was $19 \%$. The prevalence of stunted growth was $28 \%$ in the rural, $17 \%$ in the poor urban and $12 \%$ in the non-poor urban children.

The mean blood pressures (BPs) of our subjects was 99.6 (SD 10.0) $\mathrm{mmHg}$ for systolic BP and 59.6 (SD 10.3) $\mathrm{mmHg}$ for diastolic BP. The poor urban children had significantly lower systolic and diastolic BP than the non-poor urban children. On the other hand, there were no significant difference in both systolic and diastolic BP of rural children and nonpoor urban children (Table 1).
Linear regression analyses, either separately or adjusted for every other variable in the models, showed that both systolic and diastolic BPs were independently and positively related to age, HAZ and BMIZ. In the model comparing rural and non-poor urban children, a non-significant lower systolic and diastolic BPs were observed in the rural children, i.e. regression coefficients $(95 \% \mathrm{CI})$ of $-0.66(-1.45$ to 0.13$) \mathrm{mmHg}$ for systolic BP and $-0.71(-1.51 ; 0.08) \mathrm{mmHg}$ for diastolic BP. After adjustment for sex, age, HAZ and BMIZ, the association of socioeconomic status with systolic BP inversed, the systolic BP of rural children was significantly higher than those of non-poor urban children, i.e. regression coefficients $(95 \% \mathrm{CI})$ of 1.19 $(0.42 ; 1.96) \mathrm{mmHg}$. Although not statistically significant, the diastolic BP of rural children after adjustment for the above confounding factors was also higher than those of the non-poor urban children (Table not shown).

On the other hand, comparing poor urban children to non-poor urban children showed that in the unadjusted model, socioconomic status was significantly associated with both systolic and diastolic BPs, i.e. poor urban children had significantly lower systolic and diastolic BPs. But, in the model adjusted for sex, age, HAZ and BMIZ, the association between socio-economic status and BPs diminished (Table not shown). Comparing predictors of systolic and diastolic BPs showed that, within each socioeconomic status group, age, HAZ and BMIZ were independently and positively associated with both systolic and diastolic BPs (Table 2).

\begin{tabular}{|c|c|c|c|}
\hline Variables & Mean (SD) & Mean difference $(95 \% \mathrm{Cl})$ & $\mathrm{P}$ \\
\hline \multicolumn{4}{|l|}{ Height-for-age z-scores (HAZ) } \\
\hline Rural $(n=1169)$ & $-1.49(0.89)$ & $-0.61(-0.69 ;-0.54)$ & $<0.001$ \\
\hline Poor urban $(n=431)$ & $-1.27(0.85)$ & $-0.40(-0.50 ;-0.30)$ & $<0.001$ \\
\hline Nonpoor urban $(n=1322)$ & $-0.87(0.94)$ & 0 (reference) & - \\
\hline \multicolumn{4}{|c|}{ Body mass index-for-age z-scores (BMIZ) } \\
\hline Rural $(n=1169)$ & $-1.08(1.01)$ & $-0.24(-0.33 ;-0.15)$ & $<0.001$ \\
\hline Poor urban $(n=431)$ & $-1.12(1.08)$ & $-0.28(-0.40 ;-0.16)$ & $<0.001$ \\
\hline Nonpoor urban $(n=1322)$ & $-0.84(1.26)$ & 0 (reference) & - \\
\hline \multicolumn{4}{|l|}{ Systolic BP $(\mathrm{mmHg})$} \\
\hline Rural $(n=1169)$ & $99.5(9.5)$ & $-0.66(-1.45 ; 0.13)$ & 0.10 \\
\hline Poor urban $(n=431)$ & $98.4(9.6)$ & $-1.79(-2.90 ;-0.67)$ & 0.002 \\
\hline Nonpoor urban $(n=1322)$ & $100.1(10.5)$ & 0 (reference) & - \\
\hline \multicolumn{4}{|l|}{ Diastolic BP $(\mathrm{mmHg})$} \\
\hline Rural $(n=1169)$ & $59.5(10.0)$ & $-0.71(-1.51 ; 0.08)$ & 0.08 \\
\hline Poor urban $(n=431)$ & $58.5(11.3)$ & $-1.68(-2.82 ;-0.53)$ & 0.004 \\
\hline Nonpoor urban $(n=1322)$ & $60.2(10.2)$ & 0 (reference) & - \\
\hline
\end{tabular}


Of the 2922 children, 2750 (94.1\%) reported their birth weight; i.e. 1079 out of 1169 (92.3\%) rural children, 348 out of 431 (92.3\%) poor urban children and 1273 out of 1322 (96.3\%) non-poor urban children. There were no significant difference in the prevalence of having low birth weight (LBW) between the rural (7.9\%), the poor urban $(9.4 \%)$ and the nonpoor urban children $(6.9 \%)(\mathrm{P}=0.05)$. However, the non-poor urban children had significantly higher odds to have high birth weight (HBW), i.e. the prevalence of HBW of $12.4 \%$, compared to $6.8 \%$ in the rural children and $7.2 \%$ in the poor urban children.

There were no difference in the mean systolic and diastolic BP of LBW children compared to those of NBW children but there were significantly higher systolic and diastolic BP of HBW children compared to NBW children (Table 3). Since the mean HAZ and BMIZ of HBW children were also significantly higher than those of the NBW children, adjusting the regression of birth weight to BPs with BMIZ and HAZ showed that birth weight was not, anymore, a significant predictor of either systolic or diastolic BPs. The variable birth weights (Table 2) did not significantly altered the models. Within each birth weight group, systolic and diastolic BPs were significantly associated with BMIZ (data not shown).

\section{Discussion}

Our study, similar to previous studies in both developing and developed countries, showed that systolic and diastolic blood pressures (BPs) in children were positively associated with age, stature and BMI. ${ }^{6-9}$ Similar associations existed within every socioeconomic status groups studied, i.e. age, stature and BMI were significant predictors of blood pressures both in low and high socioeconomic status children.

We found that, in average, the systolic and diastolic BPs of poor urban children were lower than those of non-poor urban children, while the BPs of rural children were not significantly lower than those of the non-poor urban children. Rural children had average BPs comparable to non-poor urban children despite the fact that they had, in average, lower BMI-for-age zscores (BMIZ) and height-for-age z-scores (HAZ).

In the models comparing poor urban and nonpoor urban children, the influence of socioeconomic status on both systolic and diastolic BPs diminished after adjusting for age, stature and BMI, i.e. showing that the influence of socioeconomic status on BPs in these two groups of urban children was more related to the difference in the distribution of stature and BMI, rather than the influence of the socioeconomic status per se.

Table 2. Adjusted regression coefficients (b) for systolic and diastolic blood pressure as the dependent variables and sex, age, height-for-age z-scores (HAZ), and body mass index-for-age z-scores (BMIZ) as the independent variables in children within different socioeconomic status groups

\begin{tabular}{|c|c|c|c|}
\hline Variables & $\begin{array}{c}\text { Rural } \\
n=1169 \\
\beta^{1}(95 \% \mathrm{Cl})\end{array}$ & $\begin{array}{c}\text { Poor urban } \\
n=431 \\
\beta^{1}(95 \% \mathrm{Cl})\end{array}$ & $\begin{array}{c}\text { Nonpoor urban } \\
n=1322 \\
\beta^{1}(95 \% \mathrm{Cl})\end{array}$ \\
\hline $\begin{array}{l}\text { Sex (1=male, } 0=\text { female) } \\
\text { Age (mos) } \\
\text { HAZ } \\
\text { BMIZ } \\
\text { Constant } \\
\text { Adjusted R square }\end{array}$ & $\begin{array}{c}-0.42(-1.52 ; 0.68) \\
0.09(0.02 ; 0.16)^{\star} \\
1.80(1.19 ; 2.42)^{\star * \star} \\
2.36(1.84 ; 2.89)^{\star \star \star} \\
97.3(91.4 ; 103.3)^{\star \star *} \\
0.10\end{array}$ & $\begin{array}{c}0.72(-1.09 ; 2.52) \\
0.13(0.01 ; 0.25)^{\star} \\
1.46(0.40 ; 2.52)^{\star \star} \\
2.39(1.57 ; 3.21)^{\star \star \star} \\
90.9(80.5 ; 101.3)^{\star \star \star} \\
0.10\end{array}$ & $\begin{array}{c}1.12(0.06 ; 2.18)^{\star} \\
0.15(0.08 ; 0.23)^{\star \star *} \\
2.54(1.97 ; 3.12)^{\star \star \star} \\
2.36(1.93 ; 2.78)^{\star \star \star} \\
90.1(83.6 ; 96.6)^{\star \star \star} \\
0.18\end{array}$ \\
\hline \multicolumn{4}{|c|}{ B. Diastolic blood pressure $(\mathrm{mmHg})$} \\
\hline Variables & $\begin{array}{c}\text { Rural } \\
n=1169 \\
\beta^{1}(95 \% \mathrm{Cl})\end{array}$ & $\begin{array}{c}\text { Poor urban } \\
n=431 \\
\beta^{1}(95 \% \mathrm{Cl})\end{array}$ & $\begin{array}{c}\text { Nonpoor urban } \\
n=1322 \\
\beta^{1}(95 \% \mathrm{Cl})\end{array}$ \\
\hline $\begin{array}{l}\text { Sex (1=male, } 0=\text { female) } \\
\text { Age (mos) } \\
\text { HAZ } \\
\text { BMIZ } \\
\text { Constant } \\
\text { Adjusted R square }\end{array}$ & $\begin{array}{c}-0.98(-2.18 ; 0.21) \\
0.08(0.005 ; 0.16)^{\star} \\
1.77(1.10 ; 2.43)^{\star * \star} \\
1.11(0.54 ; 1.67)^{\star * \star} \\
56.7(50.2 ; 63.2)^{\star \star \star} \\
0.04\end{array}$ & $\begin{array}{c}-1.95(-4.16 ; 0.25) \\
0.20(0.05 ; 0.34)^{\star \star} \\
1.14(-0.15 ; 2.44) \\
1.78(0.77 ; 2.78)^{\star \star} \\
45.3(32.6 ; 58.0)^{\star \star \star} \\
0.05\end{array}$ & $\begin{array}{c}0.09(-1.00 ; 1.18) \\
0.19(0.11 ; 0.27)^{\star * *} \\
1.60(1.01 ; 2.20)^{\star \star *} \\
1.62(1.18 ; 2.06)^{\star * *} \\
46.3(39.6 ; 52.9)^{\star * *} \\
0.10\end{array}$ \\
\hline
\end{tabular}

${ }^{1} \beta$ : unstandardized coefficient with adjustment for every other variable in the model.

${ }^{*} \mathrm{P}<0.05 ;{ }^{* *} \mathrm{P}<0.01 ;{ }^{* *} \mathrm{P}<0.001$ 
Madarina Julia et al: Influence of socioeconomic status and birth weight on blood pressure

Table 3. Comparison of height-for-age (HAZ), body mass indexfor-age z-scores (BMIZ), systolic and diastolic blood pressure (BP) of children from different birth weight groups.

\begin{tabular}{|c|c|c|c|}
\hline Variables & $\begin{array}{c}\text { Mean } \\
\text { (SD) }\end{array}$ & $\begin{array}{l}\text { Mean difference } \\
(95 \% \mathrm{Cl})\end{array}$ & $\mathrm{P}$ \\
\hline \multicolumn{4}{|c|}{ Height-for-age z-scores (HAZ) } \\
\hline $\mathrm{LBW}^{1}(\mathrm{n}=193)$ & $-1.45(0.87)$ & $0.26(0.12-0.40)$ & $<0.001$ \\
\hline $\mathrm{HBW}^{2}(\mathrm{n}=242)$ & $-0.77(0.95)$ & $-0.42(-0.54-(-0.29)$ & $<0.001$ \\
\hline $\mathrm{NBW}^{3}(\mathrm{n}=2315)$ & $-1.19(0.94)$ & 0 (reference) & - \\
\hline \multicolumn{4}{|c|}{ Body mass index-for-age $z$-scores (BMIZ) } \\
\hline LBW $^{1}(n=193)$ & $-1.25(1.13)$ & $0.24(0.07-0.41)$ & 0.005 \\
\hline $\mathrm{HBW}^{2}(\mathrm{n}=242)$ & $-0.40(1.03)$ & $-0.61(-0.76-(-0.46)$ & $<0.001$ \\
\hline $\mathrm{NBW}^{3}(\mathrm{n}=2315)$ & $-1.01(1.14)$ & 0 (reference) & - \\
\hline \multicolumn{4}{|l|}{ Systolic BP $(\mathrm{mmHg})$} \\
\hline LBW $^{1}(n=193)$ & $99.54(9.43)$ & $0.061(-1.38-1.50)$ & 0.93 \\
\hline $\mathrm{HBW}^{2}(\mathrm{n}=242)$ & $102.34(11.30)$ & $2.86(1.37-4.34)$ & $<0.001$ \\
\hline $\mathrm{NBW}^{3}(\mathrm{n}=2315)$ & $99.48(9.83)$ & 0 (reference) & - \\
\hline \multicolumn{4}{|l|}{ Diastolic BP (mmHg) } \\
\hline $\mathrm{LBW}^{1}(\mathrm{n}=193)$ & $58.87(9.56)$ & $-0.71(-2.23-0.81)$ & 0.36 \\
\hline $\mathrm{HBW}^{2}(\mathrm{n}=242)$ & $61.09(10.57)$ & $1.51(0.13-2.89)$ & 0.03 \\
\hline $\mathrm{NBW}^{3}(\mathrm{n}=2315)$ & $59.58(10.40)$ & 0 (reference) & - \\
\hline
\end{tabular}

${ }^{1} \mathrm{LBW}=$ low birth weight, having a birth weight below the $10^{\text {th }}$ percentile of our study subjects' sex-specific birth weight distribution, i.e. below $2500 \mathrm{~g}$ for both boys and girls

${ }^{2} \mathrm{HBW}=$ high birth weight, having a birth weight above the $90^{\text {th }}$ percentile of our study subjects' sex-specific birth weight distribution, i.e. above $3600 \mathrm{~g}$ for boys and above $3500 \mathrm{~g}$ for girls

${ }^{3} \mathrm{NBW}=$ normal birth weight, having a birth weight between the $10^{\text {th }}$ and the $90^{\text {th }}$ percentile of our study subjects' sex-specific birth weight distribution

Comparing rural children to non-poor urban children showed different things. In the unadjusted models, systolic and diastolic BPs of rural children were not different. When the models were adjusted for sex, age, stature and BMI, the rural children had significantly higher systolic BP compared to non-poor urban children of a given stature and BMI. Although not statistically significant, similar associations were also observed for diastolic BP.

In association with birth weight, our study observed that higher birth weight children had higher systolic BP. The association was explained by higher current BMIZ and HAZ in HBW children.

The rural communities in this study seemed to be the poorest among the three SES groups studied since they had the largest prevalence of stunted growth, i.e. $28 \%$, compared to $17 \%$ in poor urban children and $12 \%$ in non-poor urban children. Stunted growth reflected long-term cumulative inadequacies of health and nutrition, and had been strongly associated with poverty. ${ }^{29,30}$ However, stunted growth was not the only risk factor for raised $\mathrm{BP}$ in these rural children, as had been suggested by a study in Brazils, ${ }^{31}$ because even in this poor population, BPs were positively associated with both height and BMI.

Poor rural communities in developing countries are at higher risk for suffering from impaired prenatal and early postnatal growth, since these are the times when growth is most vulnerable to the adverse effect of poverty, poor nutrition and high prevalence of infectious diseases. ${ }^{30,32-34}$ However, studies showed that some of these growth retarded infants did exhibit catch up growth at later ages. ${ }^{35,36}$

The associations between impaired fetal growth and raised blood pressure in later life, either in developing or developed countries, have been widely reported. ${ }^{37,38}$ Some studies have also observed the relation of rapid growth in late childhood or adolescent period to higher BP later in life. 6,36,39 Nevertheless, the influence of infant growth to later BP varies.

Walker et al. 2001, in a study in Jamaica found no difference in systolic or diastolic BPs between stunted and non stunted children. However, he reported larger effects of increasing weight on systolic $\mathrm{BP}$ of 11 to 12 years-old Jamaican children who were stunted between the age of 9 to 24 months. ${ }^{36}$ Cheung et al. observed that after controlling birth length and ponderal index, the change in ponderal index from 6 to 18 months was inversely associated with systolic BP in young Hongkong adults. ${ }^{40}$ Similarly, Adair and Cole, in a longitudinal study in The Philippines showed that growth rate in infancy was negatively associated with later $\mathrm{BP} .{ }^{39}$ On the other hand, several studies in developed countries had failed to observe any association between growth in infancy and later BP once birth weight had been taken into account. ${ }^{41,42}$

A study of 3157 people born in 1946 in Britain showed that poor childhood growth provided some of the explanation for the influence of childhood social class gradient on later blood pressure. ${ }^{23}$ However, A Finnish cohort study on people born in 1934-44 found an enhanced effect of negative association of poor childhood growth with adult BP among those grown up in poor social conditions. ${ }^{22}$ So far, it is not yet clear whether the influence of childhood socioeconomic status on later blood pressure is mediated, at least partly, through the growth in early life.

The much higher prevalence of stunted growth observed in the rural children in our study indicated that the rural community had more probability to suffer from pre- and postnatal growth restriction. If linear growth 
Madarina Julia et al: Influence of socioeconomic status and birth weight on blood pressure

retardation in early life did indeed potentiate the effects of later weight gain on blood pressure, this and the poor socioeconomic circumstances might be the explanation for the observed higher sytolic BP in the rural children in our study. But of course, due to the cross sectional nature of our study, we could not verify this hypothesis.

Albeit small, i.e. $1.19 \mathrm{mmHg}(95 \% \mathrm{CI} 0.42$ to 1.96$)$, the elevated systolic BP observed in these rural children was independent of other important predictors of BP in childhood, i.e. sex, age, stature and BMI. Studies in adults in developing countries found a difference of around 2 to $5 \mathrm{mmHg}$ between SES groups studied. ${ }^{14,16}$ Previous studies in Indonesian adults found no consistent difference in the prevalence of hypertension between rural and urban population. ${ }^{43}$ In 1986, a study in some subdistricts in Yogyakarta observed a slightly higher prevalence of hypertension in rural children (aged 6 to 14 years old) compared to urban children. ${ }^{44}$

In summary, our study indicates that the poorer segment of the population, i.e. the rural community, faced a higher risk for developing hypertension, which might be related to the observed higher prevalence of stunted growth in this community. Since one third of the children in developing countries become growth retarded before the age of 5 years, ${ }^{45}$ if linear growth retardation potentiates the effects of later weight gain on blood pressure, then stunting in early childhood will be an important contributor to the rise of cardiovascular disease in developing countries. For disease prevention, we should therefore focus on optimization of fetal and infant growth.

\section{References}

1. Bartosh SM, Aronson AJ. Childhood hypertension: an update on etiology, diagnosis, and treatment. Pediatr Clin N Am 1999;46:235-52.

2. Gillman MW, Cook NR, Rosner B, Evans DA, Keough ME, Taylor JO, et al. Identifying children at high risk for the development of essential hypertension. J Pediatr 1993; 122:837-46.

3. Li S, Chen W, Srinivasan S, Bond MG, Tang R, Urbina EM, et al. Childhood cardiovascular risk factors and carotid vascular changes in adulthood: The Bogalusa Heart Study. JAMA 2003;290:2271-6.

4. Sorof JM, Alexandrov AV, Cardwell G, Portman RJ. Carotid artery intimal-medial thickness and left ventricular hypertrophy in children with elevated blood pressure. Pediatrics 2003;111:61-6.

5. Burke GL, Arcilla RA, Culpepper WS, Webber LS, Chiang YK, Berenson GS. Blood pressure and echocardiographic measures in children: the Bogalusa Heart Study. Circulation 1987;75:106-14.

6. Schack-Nielsen L, Holst C, Sorensen TIA. Blood pressure in relation to relative weight at birth through childhood and adulthood and youth obese and non-obese adult men. Int J Obes 2002;26:1539-46.

7. Chu NF, Rimm EB, Wang DJ, Liou HS, Shieh SM. Clustering of cardiovascular disease risk factors among obese schoolchildren: the Taipei Children Heart Study. Am J Clin Nutr 1998;67:1141-6.

8. He Q, Ding ZY, Fong DY, Karlberg J. Blood pressure is associated with body mass index in both normal and obese children. Hypertension 2000;36:165-70.

9. Sorof J, Daniels S. Obesity hypertension in children: a problem of epidemic proportions. Hypertension 2002;40:441-7.

10. Vargas CM, Ingram DD, Gillum RF. Incidence of hypertension and educational attainment the NHANES I epidemiologic follow up study. Am J Epid 2000;152:272-8.

11. Colhoun HM, Hemingway H, Poulter NR. Socio-economic status and blood pressure: an overview analysis. J Hum Hypertens 1998;12:91-110.

12. Langnase K, Mast M, Muller MJ. Social class differences in overweight of prepubertal children in northwest Germany. Int J Obes Relat Metab Disord 2002;26:566-72.

13. Soekirman, Hardiansyah, Jus'at I, Jahari AB. Zulkafli H. Regional study of nutritional status of urban primary school children. West Jakarta and Bogor, Indonesia. Food Nutr Bull 2002;23:31-40.

14. Mendez MA, Cooper R, Wilks R, Luke A, Forrester T. Income, education, and blood pressure in adults in Jamaica, a middleincome developing country. Int J Epid 2003; 32:400-7 .

15. Gulliford M. Commentary: epidemiological transition and socioeconomic inequalities in blood pressure in Jamaica. Int J epid 2003;32:408-9.

16. Bovet P, Ross AG, Gervasoni JP, Mkamba M, Mtasiwa DM, Langeler C, et al. Distribution of blood pressure, body mass index and smoking habits in the urban population of Dar es Salaam, Tanzania, and associations with socioeconomic status. Int J Epid 2002;31:240-7.

17. Mbaya JCN, Minkolou EM, Salah JN, Balkau B. The prevalence of hypertension in rural and urban Cameroon. Int J Epid 1998;27:181-5.

18. Sobngwi E, Mbanya JC, Unwin NC, Porcher R, Kengne AP, Fezeu $\mathrm{L}$, et al. Exposure over the life course to an urban environment 
Madarina Julia et al: Influence of socioeconomic status and birth weight on blood pressure

and its relation with obesity, diabetes, and hypertension in rural and urban Cameroon. In J Epid 2004;33:769-76.

19. Yusuf S, Reddy S, Ounpuu S, Anand S. Global burden of cardiovascualr diseases. Part I: General considerations, the epidemiologic transition, risk factors, and impact of urbanization. Circulation 2001;104:2746-53.

20. Torun B, Stein AD, Scroeder D, Grajeda R, Conlisk A, Rodriguez $\mathrm{M}$, et al. Rural-to-urban migration and cardiovascular disease risk fctors in young Guatemalan adults. Int J Epid 2001;31:218-26.

21. Smith GD, Hart C. Life-course socioeconomic and behavioural influences on cardiovascular disease mortality: the collaborative study. Am J Public Health 2002; 92:12958.

22. Barker DJP, Forsen T, Eriksson JG, Osmond C. Growth and living conditions in childhood and hypertension in adult life: a longitudinal study. J Hypertens 2002; 20:1951-6.

23. Hardy R, Wadsworth MEJ, Langenberg C, Kuh D. Birth weight, childhood growth, and blood pressure at 43 years in a British birth cohort. Int J Epid 2004;33:121-9.

24. BPS-Statistics of D.I. Yogyakarta Province. Daerah Istimewa Yogyakarta in Figures 1999. Yogyakarta, Indonesia: BPSStatistics of D.I. Yogyakarta Province, 1999.

25. Julia M, van Weissenbruch MM, Delemarre-van de Waal HA, Surjono A. Influence of socioeconomic status on the prevalence of stunted growth and obesity in Indonesian children. Food Nutr Bull 2004;25:354-60.

26. WHO. Measuring change in nutritional status: guidelines for assessing the nutritional impact of supplementary feeding programmes in vulnerable groups. Geneva: World Health Organization, 1983.

27. Task Force on Blood Pressure Control in Children. Report of the Second Task Force on Blood Pressure Control in Children. Pediatrics 1987;79:1-25.

28. Kuczmarski RJ, Ogden CL, Guo SS, Grummer-Strawn LM, Flegal KM, Mei Z, et al. 2000 CDC growth charts for the United States: methods and development. National Center for Health Statistics. Vital Health Stat 2002;11:1-190.

29. WHO Technical Report Series. Physical status: the use and interpretation of anthropometry. Geneva: World Health Organization, 1995.

30. Adair LS, Guilkey DK. Age-specific determinants of stunting in Filipino children J Nutr 1997;127:314-20.

31. Fernandes MTB, Sesso R, Martins PA, Sawaya AL. Increased blood pressure in adolescents of low socioeconomic status with short stature. Pediatr Nephrol 2003;18:435-9.

32. Ashworth A, Morris SS, Lira PIC. Postnatal growth patterns of full-term low birth weight infants in Northeast Brazil are related to socioeconomic status. J Nutr 1997;127:1950-6.

33. Schmidt MK, Muslimatun S, West CE, Schultink W, Gross R, Hautvast GAJ. Nutritional status and linear growth of Indonesia infants in West Java are determined more by prenatal environment than by postnatal factors. J Nutr 2002;132:2202-7.

34. Julia M, Surjono A, Hakimi M. Role of breastfeeding in protecting children from malnutrition: a comparative study of nutritional status in children under two years of age in two districts in Indonesia. Pediatr Indones 2002;42:106-12.

35. Adair LS. Filipino children exhibit catch-up growth from age 2 to 12 years. J Nutr 1999;129:1140-8.

36. Walker SP, Gaskin P, Powell CA, Bennet FI, Forrester TE, Grantham-McGregor S. The effects of birth weight and postnatal linear growth retardation on blood pressure at age 11-12 years. J Epidemiol Community Health 2001; 55:394-8.

37. Huxley RR, Shiell AW, Law CM. The role of size at birth and postnatal catch-up growth in determining systolic blood pressure: a systematic review of the literature. J Hypertens 2000;18:815-31.

38. Huxley R, Neil A, Collins R. Unraveling the fetal origin hypothesis: is there really an inverse association between birth weight and subsequent blood pressure? Lancet 2002;360:659-65.

39. Adair LS, Cole TJ. Rapid child growth raises blood presure in adolescent boys who were thin at birth. Hypertension 2003;41:451-6.

40. Cheung YB, Low L, Osmond C, Barker D, Karlberg J. Fetal growth and early postnatal growth are related to blood pressure in adults. Hypertension 2000;36:795-800.

41. Law CM, Shiell AW, Newsome CA, Syddall HE, Shinebourne EA, Fayers PM, et al. Fetal, infant, and childhood growth and adult blood pressure. A longitudinal study from birth to 22 years of age. Circulation 2002;105:1088-92.

42. Forsen T, Nissinen A, Tuomilehto J, Notkola I-L, Eriksson J, Vinni S. Growth in childhood and blood pressure in Finnish children. J Hum Hyperten 1998;12:397-402.

43. Budhi-Darmojo R and Tim Monica Jakarta. Proyek Monica di Jakarta. Suatu penelitian penyakit jantung di komunitas. Medika 1991;17:275-83.

44. Wahab AS. Studies of blood pressure and prevalence of hypertension in children in some districts of Yogyakarta. Pediatr Indones 1986;26:119-26.

45. UNICEF. The state of the world's children 2005. (cited 2005 Feb 12) Available from: http://www.unicef.org/sowc05/ english/sowc05 Tables.pdf.

Paediatr Indones, Vol. 47, No. 6, November 2007 • 277 